DOI10.17805/zpu.2017.4.7

\title{
Культура как ресурс развития общества: теоретические дискуссии и опыт России*
}

\author{
Н. Н. ФЕДОТОВА
}

\author{
МОСКОВСКИЙ ГОСУДАРСТВЕННЫЙ ИНСТИТУТ МЕЖДУНАРОДНЫХ ОТНОШЕНИЙ (УНИВЕРСИТЕТ) \\ МИНИСТЕРСТВА ИНОСТРАННЫХ ДЕЛ РОССИЙСКОЙ ФЕДЕРАЦИИ
}

Статья посвящена роли культуры как ресурса развития России и некоторых других стран. В ней рассматриваются методология анализа связи общества и культуры. Обсуждается вопрос о роли культуры как ресурса развития общества в концептуальном плане.

Дается анализ ситуации, в котором рассматривается состояние ресурса российского развития, производимого культурой, и препятствия для его эффективного применения, а также намечаются возможности использовать культуру как ресурс в дальнейшем развитии общества. Данная задача решается путем обсуждения отношений государства и гражданского общества, мемориальной культуры, массовой культуры. Амбивалентность культуры позволяет ей, с одной стороны, способствовать развитию общества, быть его ресурсом, а с другой стороны, затруднять это развитие, препятствовать ему, и это может происходить в одно и то же время.

Ключевые слова: культура; культурная специфика; Россия; развитие; мемориальная культура; массовая культура; гражданское общество; культурный ресурс; мягкая сила

\section{BВЕАЕНИЕ}

3 амысел данной статьи состоит в том, чтобы рассмотреть культуру в качестве ресурса развития российского общества. Это решается путем обсуждения сложностей методологии анализа отношений «общество - культура», теоретического содержания понятия «культурный ресурс», и специфики и трудностей России в его производстве и использовании.

\section{ОБЩЕСТВО И КУАБТУРА}

Несмотря на то что понятие общества является базовым для социологии, оно не имеет однозначного определения. В разные времена и разными исследователями оно определялось по-разному. Многие работы, предметом которых является анализ общества, избегают того, чтобы дать это определение в связи с его зависимостью от теоретического направления социологии, в котором это определение дается. Одна из наиболее генерализованных трактовок того, что является обществом, это «комплексные образцы социальных отношений, которые сохраняются во времени и пространстве» (Ray, 2009: 4591). Иными словами, общество тождественно социальному.

В настоящее время осознано, что общества, даже структурно близкие друг другу, имеют свою специфику, которая относится к их экономике, политике и особенно проявляется в культуре. Введение фактора культуры связано с тем, что формализуемые отношения экономики, политики несут на себе отпечаток культурной специфики обществ, их традиций, их пути развития, географического положения, ценностей, интенций. Получивший широкий резонанс концепт культурной специфики обществ существенно изменил баланс категорий «общество» и «культура». Сегодня термин

* Публикация подготовлена в рамках поддержанного РФФИ научного проекта № 15-0300732.

The article was prepared with financial support from Russian Foundation for Basic Research, grant No. 15-03-00732. 
«культура» употребляется едва ли не чаще для характеристики обществ, чем какие-то другие черты его специфики. Если раньше общества могли исследоваться без обращения к понятию «культура» во множестве своих аспектов, то сегодня культурная особенность и специфика каждого из обществ выступает как едва ли не центральная черта его понимания. Современный английский исследователь культуры П. Бёрк сказал: «Сегодня многие люди по злободневным поводам упоминают о “культуре”, а 20 или 30 лет назад они в связи с теми же поводами говорили бы об “обществе”. Из-за популярности таких выражений все труднее сказать, что же нельзя рассматривать как “культуру” (Бёрк, 2016: 12). Это своего рода антиредукционизм, из-за которого понятие общества отчасти вытеснено понятием культуры. П. Бёрк показывает следствие этого: «Культура... получает в наследство величественную мантию религиозного авторитета, но в то же время приобретает неприятное сходство с оккупацией и нашествием, и именно между этими двумя полюсами, положительным и отрицательным, располагается сейчас данное понятие» (там же: 9). Как видим, он подчеркивает не только положительные стороны доминирования культуры как концепта, но и показывает, что подобно прежнему объяснению социального через термин «общество», сегодня оно рассматривается чаще с использование понятия «культура» и иногда даже вытеснено им. Тем самым он отмечает плюсы и минусы новой доминанты, заключающейся в переходе от термина «общество»к термину «культура».

Сегодня понятие общества не может обойтись без включения культуры, что отражено в более новых определениях понятия общества. Так в «Международной энциклопедии социальных наук» общество характеризуется как «система содействия взаимозависимым социальным отношениям в соответствии с ценностями, нормами и идеологиями разделяемой культуры...» (Pfaffenberger, 2008: 650).

\section{КУ АЬТУРА КАК РЕСУРС РАЗВИТИЯ ОБЩЕСТВА}

В настоящее время стало популярным рассматривать отдельные проявления культуры как ресурса дальнейшего развития общества. Иными словами, формула «каково общество, такова и культура» сегодня перевернута до формулы «какова культура, таково и общество». Сошлюсь на оценку сложившейся ситуации английским литературоведом Т. Иглтоном: «Как идея культура обретает значимость в четырех точках исторического кризиса: когда она становится единственной видимой альтернативой деградировавшему обществу; когда кажется, что без глубоких социальных изменений культура как искусство и утонченная жизнь становится невозможной; когда она вырабатывает термины, позволяющие группе людей или целому народу бороться за политическое освобождение; наконец, когда империалистическая власть вынуждена соглашаться с образом жизни тех, кого она стремится подчинить себе» (Иглтон, 2012: 43). То есть культура, по его мнению, выходит на передний план в ситуациях общественных кризисов, разрывов, конфликтов.

В общем и целом эти четыре пункта доминирования культуры, выделенные Иглтоном, имеют место и обозначают исторические развилки, при которых общество не удовлетворяет потребностям живущих в нем людей. Амбивалентность культуры позволяет ей, с одной стороны, способствовать развитию общества, быть его ресурсом, а с другой стороны, затруднять это развитие, препятствовать ему, и это может происходить в одно и то же время. В ряде случаев модернизационные процессы не готовы соответствовать культуре. А в других случаях культура не готова способствовать модернизационным процессам и сама требует обновления. 
В нескольких ранних статьях нами было показано содержание культурных ресурсов и их значение для общества (Федотова, 2015, 2016). Были рассмотрены коды и константы культуры, прецедентные феномены культуры, культурный капитал, идентичность и ее процессуальный характер, мягкая мощь. Способы взаимодействия ресурсов культурного развития долгое время оставались мало исследованными.

Сложность изучения взаимодействия категорий, характеризующих культурные ресурсы, связана помимо недостаточного интереса к этому вопросу с отсутствием образцов, которые раскрывали бы эту связь. Нами рассмотрено в отдельной статье взаимодействие идентичности и мягкой мощи (Федотова, 2016). Это в сегодняшних реалиях выступает в качестве важнейшего отношения в связи с неблагополучием в международных делах, растущими антагонизмами между многими странами. Мягкая мощь предполагает бо́льшую возможность мирных решений в отношениях между разными странами на основе присущей им идентичности и способности понимать идентичность другого. Коды и константы культуры позволяют выделить устойчивые тенденции культуры, сопряженные с идентичностью общества, стремясь создать альтернативу взаимопонимания. Но иногда они бывают слишком различны для того, чтобы этого достичь. Уровень российско-американских отношений сегодня является примером последнего, хотя в истории наших стран имеются времена взаимопонимания и участия в совместно принятых решениях. Константы культуры вырабатываются в ходе исторического развития обществ, а коды культуры совмещают результаты исторического развития с изменчивостью в связи с новыми потребностями, объективными изменениями, конфликтами, войнами и др.

Многие исследователи, пишущие о культуре, считают, что она автоматически является капиталом - культурным капиталом. Однако это далеко не всегда так. Культурные явления становятся капиталом тогда, когда они участвуют в решении злободневных проблем предотвращения расколов, намечают тенденции позитивного развития того или иного общества. То есть тогда, когда превращаются из «пассива» в «актив» развития. Разделение общества и культуры имеет методологический характер, определяющий наиболее активного агента изменений. Возможности культуры в этом плане были рассмотрены в выдающейся работе «Культура имеет значение. Каким образом ценности способствуют общественному прогрессу», изданной уже достаточно давно, но имеющей непреходящую ценность (Культура имеет значение ... , 2002). Американский политолог С. Хантингтон в предисловии к этой книге согласился с мнением, что характеристику роли культуры можно выразить следующим образом: «С точки зрения консерватора... именно культура, а не политика определяет успех того или иного общества. В свою очередь, либерал полагает, что политика способна преобразовывать культуру и ограждать ее от самой себя» (Хантингтон, 2002: 11).

Остановимся более подробно на концепции, разрабатываемой известными учеными Р. Инглхартом и К. Вельцелем на основе сравнительных международных исследований. Они выделяют два типа ценностных установок - «ценности выживания», характеризующие экономически неразвитое традиционное общество и его культуру, и «ценности самовыражения», которые свойственны индустриальному экономически успешному обществу постматериальной культуры. Ценности выживания и ценности самовыражения противоположны: ценности выживания требуют почтения по отношению к власти, поощряют абсолютные стандарты и религию, в то время как ценности самовыражения рациональны и включают межличностное доверие, терпимость, 
благосостояние, соучастие и участие в принятии решений. Центральный тезис авторской концепции: «Социально-экономическая модернизация приводит к ослаблению внешних ограничений свободы выбора, увеличивая материальные, когнитивные и социальные ресурсы личности. Это приводит к усилению акцента на ценностях самовыражения, а оно, в свою очередь, ведет к нарастанию в обществе требований в пользу гражданских и политических свобод, гендерного равенства и “отзывчивости” властей... способствуя формированию и укреплению институтов, в наибольшей степени соответствующих максимальной свободе выбора, - одним словом, демократии» (Инглхарт, Вельцель, 2011: 12).

Свою основную идею авторы кратко выражают с помощью следующей схемы: экономические изменения (жизненная защищенность) приводят к культурным изменениям (доминированию ценности самовыражения), что, в свою очередь, вызывает политические изменения (демократические институты) (там же: 200). Конечно, такая позиция может быть подвергнута критике, поскольку, по мнению многих исследователей, между демократическим опытом и формированием гражданской культуры может быть также обратная связь или хотя бы двустороннее влияние (см.: Levitt, 2005: 367). Нельзя согласиться также с абсолютной поляризацией этих ценностей, например, при ухудшении экономического положения «ценности выживания» будут определять поведение, смыкаясь с «ценностями самовыражения».

Культура как ресурс развития может иметь достаточно серьезные ограничения. Так, известный американский политолог и социолог Ф. Фукуяма показывает, что «культура может объяснить истоки, но никак не стойкость демократии как политической системы» (Фукуяма, 2008: Электронный ресурс). Мы показали некоторые возможности влияния культуры на политическую сферу. Однако в целом в этой и ряде других концепций значение культуры поднимается до статуса культурного капитала, приводящего к серьезным изменениям в политике, экономике, в обществе в целом. Когда мы говорим о культуре как о ресурсе, то предполагаем, что это может быть использовано инструментально, т. е. для достижения определенных целей. У такого использования всегда будут ограничения, которые рассмотрим ниже.

Мы выступаем за совмещение методологии натурализма и конструктивизма в трактовке культуры как ресурса, т. е. полагаем, что эти подходы выступают как границы Аруг друга. Если, как показывает С. Хантингтон, «ключевая проблема в том, способно ли политическое руководство противодействовать социальному краху, поощряя преобразование культуры» (Хантингтон, 2002: 12), то можно закдючить, что совместная работа двух подходов представляет собой определенное решение проблемы. Наличное состояние культуры и других сфер и институтов общества является натуралистическим ограничением для конструктивистских устремлений политиков, а конструктивистские позиции, в свою очередь, проектируют границы возможного нового состояния культуры и институтов с учетом их исходного состояния.

\section{КУАБТУРА КАК РЕСУРС РОССИИ}

Как показали авторы книги «Многоликая глобализация», государственная модель мягкой мощи СССР ориентировала на предлагаемые ею параметры (например, на изучение русского языка в странах социалистического лагеря), а США, по мнению авторов этой книги, представляет свои требования после распада СССР в качестве приглашающей модели («вы можете учить английский язык») (Многоликая глобализация ..., 2004: 162), но это приглашение могучей державы мира рассматривалось многими как 
шанс улучшения жизни подобно тому, как изучение русского языка было шансом вхождения в элиты социалистических и развивающихся стран. Аанная разница в стиле не может скрыть сходства описанных процессов. Они состояли в привлечении на свою сторону людей из других стран как Западом, так и Советским Союзом. Но в этом «приглашении» есть огромное количество обязательств, которые позже проявляются. Например, требования к постсоветским и постсоциалистическим странам, входящим в ЕС, принимать мигрантов.

Богатейшие пласты культуры в ряде стран не работают в качестве культурного капитала, а выступают либо как артефакты прошлого, либо как оставленная на будущее перспектива, и их использование нередко на деле оборачивается конфликтами, вызванными размежеванием поколений, исторического опыта и современной ситуации, а также изменчивостью международных альянсов разных стран. Существенным фактором этих изменений являются стремление США распространить свою мягкую мощь на другие страны, включая Китай и Россию, борьба России за влияние в мире и легитимность своих целей, интересов и представлений как присущих населяющим ее народам, а также нехватка мягкой мощи Китая при всем ее эффективном росте, чтобы занять лидирующие позиции в мире. По мнению Аж. Ная, автора термина «мягкая мощь» и публикаций на эту тему, Россия и Китай относятся к одному кластеру стран по уровню әффективности мягкой мощи. Такое заключение вытекает из оценки Наем ошибок, совершаемых этими двумя странами, которые состоят в том, что в них производство мягкой мощи сосредоточено в руках государства, а на значимость других источников не обращается должного внимания: «Большая часть американской мягкой мощи производится гражданским обществом - всеми, от университетов и фондов до Голливуда и поп-культуры, - а не правительством» (Nye, 2013: Электронный ресурс). Именно это участие гражданского общества, бизнеса, науки и других неполитических институтов и позволяет США быть привлекательными в глазах людей других стран: «Иногда Соединенным Штатам удается сохранить определенный уровень мягкой мощи благодаря их критическому и не подлежащему цензуре гражданскому обществу, даже тогда, когда действия правительства - например, вторжение в Ирак - напротив, подрывают ее» (там же).

Иными словами, Аж. Най утверждает, что, пока правительство делает какие-то ошибки, гражданское общество и вся культурная индустрия работают на имидж страны. Говоря об этом, Най все-таки не считает, что американцы от элиты до масс заняты производством мягкой мощи, но он показывает результирующую их совместной деятельности, которая проявляет себя как гражданская сила. Ошибки правительства не могли быть исправлены только мягкой мощью гражданского общества, в том числе и потому, что уровень гражданского общества в значительной мере и в США, и в других странах, включая Россию, критически или позитивно соотнесен с политикой правительства. Верно в приведенной цитате Ная то, что культурные продукты и научные изобретения, достижения в бизнесе, результаты информационных революций сформировали в США среду, которая генерирует огромную мягкую мощь.

В отличие от США Россия после распада СССР оказалась в тяжелом экономическом положении, ибо обратилась прежде всего к политической составляющей нового общества. Она провозгласила идеи демократии еще до того, как они могли быть воплощены - в условиях конфликта по поводу произошедших изменений, безработицы, бедности, невыплаты зарплат, потерь территорий. И сегодня в России сохраняется конфликт - неолибералов и государственников, позиции которых противостоят 
друг другу и формируют своего рода два гражданских сообщества. В сравнении с Россией американские республиканцы и демократы не являются такими антагонистами между собой, будучи патриотами США. Сегодняшний конфликт между правительством Трампа и либеральной элитой показывает, как легко могут быть подорваны подобные установки. Но даже от этого американская элита не перестает быть в целом патриотической, а сектора общества не перестают генерировать мягкую мощь, компенсируя в какой-то степени внутриполитические конфликты.

Мы же в сравнении с США имеем тысячелетнюю историю, но после распада СССР прошло 27 лет, и за эти годы гражданское общество не в полной мере сформировалось, не в последнюю очередь из-за непримиримости либеральных и патриотических элит. Поэтому гражданское общество продуцирует здесь в большей мере разные ценности и идеологии. Это затрудняет как выбор целей развития, так и использование культуры как ресурса. Исторически для Китая и России государство играло огромную роль на протяжении веков. И государствоцентричная модель выступает как фактор культуры этих стран. Несмотря на то что наша история всегда была в значительной мере государствоцентрична, сейчас за упомянутые 27 лет произошли большие изменения, связанные с активностью неправительственной сферы (поток переводов и публикаций иностранных книг, ручейки обучения иностранцев в российских университетах и российских студентов за рубежом, мировая открытость науки, импорт продукции высокой и массовой культуры, туризм и др.). Опыт России показывает, что уход государства от решения проблем и ответственности за общество (1990-е годы) не менее опасен, чем попытка управлять централизованно и сверху всеми процессами на протяжении большей части нашей истории. Взаимоотношения гражданского общества и государства, позволяющие сохранить свободу и управляемость, еще долго будут устанавливаться в России в связи со спецификой ее исторического опыта. Это будет затруднять использование внутри страны ресурса российской культуры, который государством часто понимается как мемориальный (взращенный победами и страданиями народа, а также апеллирующий к высокой и народной культуре), а обществом как актуальный запрос на улучшение жизни. Аюди принимают и мемориальный дискурс, о чем свидетельствуют, например, шествие «Бессмертный полк», обращение к религиозным истокам, собственным традициям, в том числе изобретенным, и гордость за прецедентные феномены - успехи, которые впервые совершены Россией и которые указывают на ее авторство (победа в Великой Отечественной войне, освоение космоса, изобретения и пр.).

Культурные ресурсы самой России - дореволюционной и советской - сегодня недостаточно используются. Отчасти словесное совмещение ценностей досоветской, советской и постсоветской әпохи иногда выступает как оксюморон, в котором жертвы несправедливости не получают возможного оправдания. Это постулируемое сложение разных эпох сегодня весьма часто имеет непреодоленные противоречия. Ааже профессиональные историки не всегда могут предложить способы их решения, если не встанут на чью-то сторону. Это попыталась сделать на опыте Германии известный историк А. Ассман, показав изменение в сознании немцев за последние 30 лет, когда они попытались выйти из драм и противоречий прежних эпох: «Становление мемориальной культуры и падение веры в модернизацию непосредственно связаны друг с другом... Новая мемориальная культура радикально изменила традиционные формы коммеморации (совместной памяти. - $Н$. Ф.). Впервые за всю историю они относятся не только к понесенным собственной страной жертвам войны, скорбно оплаки- 
ваемым или чествуемым как герои, но и к жертвам собственных преступлений, ответственность за которые ложится на государство и последующие поколения. Подобная самокритичная коммеморация является совершенно новым историческим явлением» (Ассман, 2016: 7).

Ассман впервые предложила новую методологию, несущую попытку примирения в немецкое общество не только для него самого, но и для других стран с драматической историей. Ее позиция чрезвычайно немецкая, ибо, когда англичан упрекают, что они участвовали в иракской войне, они отвечают «это не мы, это Тони Блэр», сбрасывая в себя ответственность и приписывая ее определенному историческому персонажу, как будто тогда была совсем другая страна. В случае России методология Ассман может сработать в плане памяти о красных и белых, сторонниках и противниках революции, сталинских репрессиях и рывке страны от аграрного к индустриальному обществу, распаде СССР как трагедии и как шансе нового развития и пр. Тем более что, как пишет Ассман, «несмотря на очевидные проблемы и порой ложные пути их решения, мемориальная культура является несущей опорой гражданского общества» (там же: 9). Германии такая позиция помогает развить мягкую мощь, состоящую из «правового общественного порядка, способной к кооперации внешней политики, но также и из литературного и музыкального наследия великих классиков, из инновационного инженерного искусства, впечатляющего чемпионата мира по футболу или силы урбанистической привлекательности столицы Берлина... Высокий финансовый вклад в развитие сотрудничества и гуманитарную помощь по всему миру тоже факторы германской мягкой силы, значение которых нельзя недооценивать» (Пуле, 2017: Электронный ресурс). То есть такая трактовка истории выступает фактором рефлексии истории и культуры и их способности стать культурным ресурсом страны.

Сегодня жизнь в российском обществе, как и в других обществах - американском, китайском, немецком и др., - является жизнью людей в массовом обществе, которому свойственно массовое производство, массовое потребление, массовая культура. Массовая культура с позиций высоких художественных достижений рассматривается как упрощенная, посредственная, как вид развлечения, времяпрепровождения. Аж. Най ссылается на А. де Токвиля: «...при демократии нет классовых или гильдевых ограничений на продукцию ремесленников, превалирует вкус масс. К тому же коммерческие интересы в капиталистической экономике направлены на эксплуатацию обширных рынков, что часто имеет своим результатом низкий общий культурный знаменатель» (Най, 2006: 80). Най показывает, что критический взгляд интеллектуалов и элит на массовую культуру вызван, скорее, ее коммерциализмом, развлекательным характером и незначительным политическим эффектом. Най согласен, что американская массовая культура включает в себя «блеск, секс, насилие, безвкусие и материализм» (там же). Вместе с тем он также солидаризируется с тем, что она «создает образ американских ценностей, которые открыты, мобильны, индивидуалистичны, направлены против истеблишмента, плюралистичны... и свободны», и с тем, что этот контекст более могуществен, чем политика или экономика, он движет политику и экономику (там же). Мы уже показывали в наших статьях, что Най считает одной из причин поражения СССР в холодной войне отсутствие привлекательной массовой культуры. И сегодня в России массовая культура адекватного качества пока, к сожалению, представлена единичными экземплярами фильмов, сериалов, передач, музыкальных исполнителей и пр. И это выступает серьезным ограничителем как транс- 
ляции хороших культурных образцов внутри страны, так и возможностей представить их для русскоязычной аудитории постсоветского пространства и на мировом культурном поле.

В отличие от Ная английский исследователь культурных индустрий отмечает, что США добились господства на мировом культурном рынке, в частности в плане массовой культуры, наряду с фактором объема и природы их внутреннего рынка досуга, с помощью активной роли государства: «Правительственные организации играли ощутимую роль в продвижении за границей своих культурных индустрий, используемых в качестве средства обеспечения дохода от экспорта, а также для экспортирования определенного комплекса убеждений и ценностей, связанных с организацией производства и потребления... Помощь, поступавшая из США (в Европу. - Н. Ф.) в послевоенный период, была привязана к обещаниям не препятствовать их культурному экспорту» (Хезмондалш, 2014: 291). То есть в случае США речь идет об усилиях государства, предпринимаемых для распространения культурных представлений за рубеж, а не о его ответственности за их производство.

Культура стран является источником их развития и одновременно ограничивает их возможности. Русская культура признана во всем мире. Художественные достижения, выдающуюся музыку, великую литературу и величие и стойкость народа, достойно прошедшего сквозь века в войнах и в строительстве мирной жизни, и другие позитивные качества завоевали симпатию в мире. Однако фактически это образцы высокой и народной культуры, которые в силу своего охвата уступают массовой культуре.

Надо признать, что ограничители возможности работы культуры как ресурса имеют свои истоки в российской культуре, для которой характерна идеализация особых форм хозяйства, поведения, в которых ведется поиск наиболее желаемого идеального варианта. Этот идеализм не дает предположить негативные последствия изменений, учесть реальный ход последующих за изменениями событий, и способ развития путем разрушения старого общества и перехода к новому неоднократно пройден. Схожие и другие препятствия для использования культуры как ресурса присущи и другим обществам.

Вместе с тем ограничителем в России выступает то, что группы ее населения, а иногда и правительство стремятся к быстрым и простым решениям. Как показал известный политолог А. Е. Фурман, события 1991 г. - распад СССР - не означали возможности перехода к западной демократии, и, как он пишет, такой переход даже «не просматривался». То есть распад СССР не был переходом к либеральной демократии и не мог означать этого в стране, в которой не было такого опыта. «Подъем» России с колен не означал конфронтации с Западом, но объективно уменьшил возможности сотрудничества в их отношениях. Социальная мобильность граждан, по мнению этого автора, была организована «по-бюрократически». Все кризисы предстают россиянам как неожиданные (Фурман, 2010: 25-37, 116-127, 135-138, 148-159).

Аж. Най во многом исходит из ощущения, что применение американской модели развития может решить проблемы модернизации таких стран, как Китай и Россия, поскольку путь известен. Однако в этой позиции произошло игнорирование важнейшего фактора - культуры, которая складывалась исторически различно в России, Китае и США. А следовательно, чужая модель может помочь, но она не прорастет всю толщу общества, не сможет изменить его культурные особенности, даже если добьется успехов в отдельных направлениях. Известный российский экономист А. Аузан дал очень правильную, на наш взгляд, оценку возможности использовать культурный 
ресурс: «...медианное по сравнению с другими странами значение по индивидуализму и коллективизму - это совсем не недостаток России и не только основание для многовековых споров западников и славянофилов, но еше и возможность применения как восточных, так и западных экономических, социальных и управленческих технологий, и дополнительные опции для развития» (курсив мой. - Н. Ф.) (Аузан, 2017: Электронный ресурс).

\section{ЗАКАЮЧЕНИЕ}

Рассмотренная дилемма «социальное - культурное» действительно существует. В одни периоды культура выступает как ведущая сила развития общества, в другие социальное выходит на передний план. Сегодня существуют культурные индустрии, которые связаны с техникой и технологиями производства культуры - фильмов, передач, музыкальных шоу и пр. Именно культурные индустрии заставили их исследователей обратить внимание на то, что и сведение к социальному и сведение к культурному могут стать типами редукции, подобно тому как возможны экономические, технологические, политические, социальные и культурные редукции.

На наш взгляд, редукция к социальному или культурному при изучении процессов социальной жизни может происходить. Аля избегания таких редукций, если они происходят, важен комбинированный социально-культурный подход. По мнению английского исследователя культурных индустрий Аж. Хезмондалша, концепция социокультурного является «нередукционистской по своей природе, включающей в себя взаимодействия между культурными сферами и более широкими социальными системами и поведением...» (Хезмондалш, 2014: 118). Представляется, что исследования с позиций культуры и с позиций общества не обязательно являются редукционистскими, поскольку в каждом обществе на передний план может выступить одна из этих характеристик. В России, на наш взгляд, социокультурные, социоэкономические, социополитические проблемы в большей мере раскрывают сущность общества, культуры, экономики, политики, поскольку современная Россия строит себя в постсоветский период на новых основаниях и сведение к одному из них действительно может иметь черты редукционизма.

Исходя из отмеченных ограничений использования культуры как ресурса развития России, можно сделать выводы о необходимых изменениях, включающих более требовательное отношение к продукции массовой культуры для повышения ее уровня; развитие мемориальной культуры как одной из основ гражданского общества и хранителя его памяти; переопределение отношений «гражданское общество - государство» для обеспечения одновременно свободы и управляемости общества, которое, в том числе, позволит направить потенциал гражданского общества на производство мягкой мощи, и пр.

\section{СПИСОК АИТЕРАТУРЫ}

Ассман, А. (2016) Новое недовольство мемориальной культурой. М. : Новое литературное обозрение. 232 с.

Аузан, А. (2017) Промежуточные институты. Почему в России нельзя построить все сразу [Электронный ресурс] // Московский центр Карнеги. URL: http://carnegie.ru/commentary/ 73216 (дата обращения: 22.09.2017).

Бёрк, П. (2016) Что такое культуральная история? М. : Изд. дом Высшей школы экономики. 240 с. 
Иглтон, Т. (2012) Идея культуры. М. : Изд. дом Высшей школы экономики. 192 с.

Инглхарт, Р., Вельцель, К. (2011) Модернизация, культурные изменения и демократия. Последовательность человеческого развития. М. : Новое издательство. 464 с.

Культура имеет значение. Каким образом ценности способствуют общественному прогрессу (2002) / под ред. $\Lambda$. Харрисона и С. Хантингтона. М. : Московская школа политических исследований. 320 с.

Многоликая глобализация. Культурное разнообразие в современном мире (2004)/ под ред. П. Бергера и С. Хантингтона. М. : Аспект Пресс. 382 с.

Най, Аж. (2006) Гибкая власть: как добиться успеха в мировой политике. М. : ФСПИ «Тренды». $221 \mathrm{c}$.

Пуле, В. (2017) Больше мягкой силы для Европы! [Электронный ресурс]// ИноСМИ. 1 августа. URL: http://inosmi.ru/politic/20170801/239948657.html (дата обращения: 28.08.2017).

Федотова, Н. Н. (2015) Концептуальные средства анализа российской культуры // Знание. Понимание. Умение. № 4. С. 36-53. DOI: 10.17805/zpu.2015.4.4

Федотова, Н. Н. (2016) Анализ культурных ресурсов: мягкая мощь и идентичность // Знание. Понимание. Умение. № 4. С. 55-69. DOI: 10.17805/zpu.2016.4.4

Фукуяма, Ф. (2008) Самуэль Хантингтон, 1927-2008. In memoriam. [Электронный ресурс]// Русский журнал. URL: http://www.russ.ru/layout/set/print/pole/Samuel-Hantington-1927-2008 (дата обращения: 14.08.2017).

Фурман, А. Е. (2010) Авижение по спирали. Политическая система России в ряду других систем. М. : Весь мир. 165 с.

Хантингтон, С. Предисловие. Культуры - это серьезно // Культура имеет значение. Каким образом ценности способствуют общественному прогрессу (2002) / под ред. $\Lambda$. Харрисона и С. Хантингтона. М. : Московская школа политических исследований. 320 с. С. 9-14.

Хезмондалш, А. (2014) Культурные индустрии. М. : Высшая школа экономики. 456 с.

Levitt, B. (2005) Political Culture and the Science of Politics // Latin American Research Review. Vol. 40. № 3. P. 365-376.

Nye, J. (2013) What China and Russia Don't Get About Soft Power. Beijing and Moscow are trying their hands at attraction, and failing - miserably [Электронный ресурс] // Foreign Policy. 29 апреля. URL: http://foreignpolicy.com/2013/04/29/what-china-and-russia-dont-get-about-softpower/ (дата обращения: 15.08.2017).

Pfaffenberger, B. (2008) Society // International Encyclopedia of the Social Sciences. V. 4. Ed. by William A. Darity Jr. N. Y., London : Macmillan. P. 650-653.

Ray, L. (2009) Society // The Blackwell Encyclopedia of Sociology. Ed. by G. Ritzer. Oxford, Malden : Blackwell Publishing. 5658 p. P. 4589-4591.

Lата поступления: 12.09 .2017 2.

\section{CULTURE AS A RESOURCE OF SOCIAL DEVELOPMENT: \\ THEORETICAL DISCUSSIONS AND RUSSIA'S EXPERIENCE \\ N. N. FEDOTOVA \\ MOSCOW STATE INSTITUTE OF INTERNATIONAL RELATIONS (MGIMO UNIVERSITY), MINISTRY OF FOREIGN AFFAIR OF THE RUSSIAN FEDERATION}

The article is devoted to the role of culture as a resource of social development of Russia and several other countries. It considers the analysis methodology of the connection between society and culture. The article also discusses the role of culture as a resource of social development in the conceptual context.

The author gives the analysis of the situation which considers the recourse of Russian social development generated by culture, and the obstacles to its effective application; also, the opportunities for using culture as a resource in future social development are outlined. This problem can be solved by discussing the relationship between the state and the civil society, memorial culture and mass cul- 
ture. On the one hand, the ambivalence of culture allows it to foster social development and to be its resource; on the other hand, it can hinder and inhibit this development, which can occur coincidently.

Keywords: culture; cultural particularities; Russia; development; memorial culture; mass culture; civil society; cultural resource; soft power

\section{REFERENCES}

Assman, A. (2016) Novoe nedovol'stvo memorial'noi kul'turoi. Moscow, Novoe literaturnoe obozrenie. 232 p. (In Russ.).

Auzan, A. (2017) Promezhutochnye instituty. Pochemu v Rossii nel'zia postroit' vse srazu. Moskovskii tsentr Karnegi [online] Available at: http://carnegie.ru/commentary/73216 (access date: 22.09.2017). (In Russ.).

Berk, P. (2016) Chto takoe kul'tural' naia istoriia? Moscow, Izd. dom Vysshei shkoly ekonomiki. 240 p. (In Russ.).

Iglton, T. (2012) Ideia kul'tury. Moscow, Izd. dom Vysshei shkoly ekonomiki. 192 p. (In Russ.).

Inglkhart, R. and Vel'tsel', K. (2011) Modernizatsiia, kul'turnye izmeneniia $i$ demokratiia. Posledovatel' nost' chelovecheskogo razvitiia. Moscow, Novoe izdatel'stvo. 464 p. (In Russ.).

Kul' tura imeet znachenie. Kakim obrazom tsennosti sposobstvuiut obshchestvennomu progressu (2002) / ed. by L. Kharrison and S. Khantington. Moscow, Moskovskaia shkola politicheskikh issledovanii. 320 p. (In Russ.).

Mnogolikaia globalizatsiia. Kul'turnoe raznoobrazie $v$ sovremennom mire (2004) / ed. by P. Berger and S. Khantington. Moscow, Aspekt Press. 382 p. (In Russ.).

Nai, Dzh. (2006) Gibkaia vlast': kak dobit'sia uspekba v mirovoi politike. Moscow, FSPI «Trendy». 221 p. (In Russ.).

Pule, V. (2017) Bol'she miagkoi sily dlia Evropy! InoSMI. 1 August [online] Available at: http://inosmi.ru/politic/20170801/239948657.html (access date: 28.08.2017). (In Russ.).

Fedotova, N. N. (2015) Kontseptual'nye sredstva analiza rossiiskoi kul'tury. Znanie. Ponimanie. Umenie, no. 4, pp. 36-53. DOI: 10.17805/zpu.2015.4.4 (In Russ.).

Fedotova, N. N. (2016) Analiz kul'turnykh resursov: miagkaia moshch' i identichnost'. Znanie. Ponimanie. Umenie, no. 4, pp. 55-69. DOI: 10.17805/zpu.2016.4.4 (In Russ.).

Fukuiama, F. (2008) Samuel' Khantington, 1927-2008. In memoriam. Russkii zhurnal [online] Available at: http://www.russ.ru/layout/set/print/pole/Samuel-Hantington-1927-2008 (access date: 14.08.2017). (In Russ.).

Furman, D. E. (2010) Dvizhenie po spirali. Politicheskaia sistema Rossii v riadu drugikb sistem. Moscow, Ves' mir. 165 p. (In Russ.).

Khantington, S. Predislovie. Kul'tury - eto ser'ezno. In: Kul'tura imeet znachenie. Kakim obrazom tsennosti sposobstvuiut obshchestvennomu progressu (2002) / ed. by L. Kharrison and S. Khantington. Moscow, Moskovskaia shkola politicheskikh issledovanii. 320 p. Pp. 9-14. (In Russ.).

Khezmondalsh, D. (2014) Kul'turnye industrii. Moscow, Vysshaia shkola ekonomiki. 456 p. (In Russ.).

Levitt, B. (2005) Political Culture and the Science of Politics. Latin American Research Review, vol. 40, no. 3, pp. 365-376.

Nye, J. (2013) What China and Russia Don't Get About Soft Power. Beijing and Moscow are trying their hands at attraction, and failing - miserably. Foreign Policy, 29 April [online] Available at: http://foreignpolicy.com/2013/04/29/what-china-and-russia-dont-get-about-soft-power/ (access date: 15.08.2017).

Pfaffenberger, B. (2008) Society. In: International Encyclopedia of the Social Sciences, vol. 4. Ed. by William A. Darity Jr. N. Y., London, Macmillan. P. 650-653.

Ray, L. (2009) Society. In: The Blackwell Encyclopedia of Sociology. Ed. by G. Ritzer. Oxford, Malden, Blackwell Publishing. 5658 p. P. 4589-4591. 
Федотова Надежда Николаевна - доктор социологических наук, профессор кафедры социологии Московского государственного института международных отношений (Университета) Министерства иностранных дел Российской Федерации. Адрес: 119454, Россия, г. Москва, пр. Вернадского, д. 76. Тел.: +7 (495) 434-94-26. Эл. адрес: nnfedotova@rambler.ru

Fedotova Nadezhda Nikolayevna, Doctor of Sociology, Professor, Department of Sociology, Moscow Institute of International Relations (MGIMO University), Ministry of Foreign Affairs of the Russian Federation. Postal address: 76, Vernadskogo Ave., Moscow, Russian Federation 119454. Tel.: +7 (495) 434-94-26. E-mail: nnfedotova@rambler.ru

DOI10.17805/zpu.2017.4.8

\title{
Современный язык: «вместилище культуры» или форма социокультурной адаптации?
}

\author{
А. В. КОСТИНА \\ МОСКОВСКИЙ ГУМАНИТАРНЫЙ УНИВЕРСИТЕТ
}

В статье рассматриваются новые языковые явления, формирование которых обусловлено развитием научно-технических, социальных, экономических, культурных факторов. Это сетевая литература и ее новые формы и жанры, выполняющие различные функции начиная от языковых, эстетических, познавательных до социальных и коммуникативных. Автор показывает, что сегодня понятие «литература» означает новое явление, прежде всего связанное с возможностью свободного публичного высказывания. Показано, что на изменение социокультурной среды моментально реагирует язык, в том числе посредством создания не только целой системы неологизмов, но и принципиально новых языковых форм.

Названия новых жанров сетевой литературы, как правило, представляют собой транскрипции англоязычных названий. В силу своей сжатости в пространстве и во времени она апеллирует преимущественно к тем ситуациям, которые выступают как наиболее сильные раздражители. Сетевая литература использует такие свойства Сети, как нелинейность и опора на гиперссылки, благодаря которым образуется гипертекст; интерактивность, позволяющую вторгаться в текст, дописывать его или, по крайней мере, разгадывать.

Все тексты, выложенные в Сеть, можно разделить на две группы. Первые созданы по законам линейного текста и могут быть расположены на определенных ресурсах - библиотеках, журналах и т. д. Вторая группа текстов создана совершенно по другим законам, которые определяются особенностями строения самой Сети, главными признаками которой выступают создание киберпространства и нового времени - вневременного.

Главное качество сетевой литературы - социальность. Именно сетевая коммуникация выступает как полноценный заменитель реального, живого общения, осуществляющегося непосредственно. Социальные группы в Сети различны по численности; входящие в эти сообщества преследуют разные цели; они различны по степени включенности в сетевую жизнь. Отмечается существенное влияние сетевой культуры на культуру в целом. Сетевые формы коммуникации соответствуют потребностям и ожиданиям людей и отражают те доминантные смыслы культуры, которые, складываясь в сетевых сообществах, распространяются в обществе в целом.

Ключевые слова: литература; язык; культура; социокультурная ситуация; сетевая литература; глобализация; Интернет; информационное общество; Сеть 